\title{
- 6 - n
}

\section{O Diabo em Película: Jean Epstein e o cinema dos sonhos}

\section{Lídia Rogatto e Silua'}

\section{EPSTEIn, Jean. Le Cinéma du Diable.}

Paris: Jacques melot, 194?.

\section{Resumo}

O presente trabalho oferece uma leitura do texto "O Cinema do Diabo" (1947), de Jean Epstein. Estuda-se a maneira como o teórico e cineasta francês versa sobre a influência do livro e da imagem cinematográfica, bem como a aproximação do cinema com o sonho/devaneio. Também serão discutidos os aspectos da individualidade na tela e o da função pública e útil do cinema. Para tanto, a metodologia empregada foi a pesquisa bibliográfica e a referência a filmes nos quais se exibe uma lógica onírica. Dono de relevância e consistência, "O Cinema do Diabo" expõe considerações de fácil transposição para a atualidade e, contudo, parece ecoar o objeto de seu autor - o de um cinema puro, ainda distante das telas contemporâneas.

Palauras-chaue: Jean Epstein; Cinema; Sonho; Catarse.

Quando Le cinéma du diable, um dos últimos textos do francês Jean Epstein (18971953), foi escrito em 1947, a sétima arte já deixara de ser muda e começara a desenvolver o processo Technicolor. A configuração do filme de então não passaria por muitas etapas até que chegasse à atual e, apesar das inovações oriundas do cinema digital e 3D, as concepções da imagem fílmica por Epstein conservam uma profunda atualidade.

No texto, o artesão da avant-garde francesa $^{2}$ delineia as características e a arquitetura do filme a partir da apresentação de um painel meticuloso que aponta as

\footnotetext{
${ }^{1}$ Estudante do $4^{\circ}$ ano de Comunicação Social/Jornalismo da Faculdade Cásper Líbero, São Paulo (SP).
} 
diferenças entre as naturezas do cinegrama e do texto. Para Epstein, o cinema é dono de uma lógica bastante próxima da realidade que pretende representar, requerendo mínima decodificação. Diferentemente do livro, o filme é incapaz de abstrair e formular deduções, limitando-se ao espírito da geometria para atingir a emotividade do espectador.

Esta bifurcação se deve, em primeiro lugar, à dependência da razão na captação do significado de cada suporte. O teórico natural de Varsóvia julga que ao contrário da palavra - um criptograma cartesiano que só alcança determinado efeito após operações intelectuais calcadas na lógica -, o cinema atinge seu refinamento independentemente da sensibilidade e da capacidade racional do espectador. Por esse e outros motivos, Epstein o qualifica como a mais "vulgar" e "demoníaca" das artes do espetáculo - i.e., uma manifestação que não possui regras fixas, dona de uma gramática própria ${ }^{3}$ e movida pela "preguiça intelectual".

Contudo, a constatação de que a leitura desenvolve qualidades superiores - o texto partiria da lógica para só depois governar o sentimento - não diminui o valor da sétima arte, que é calcada nas faculdades primitivas humanas (a emoção e a indução). Como o autor indica, "si le livre a reçu son antidote dans le cinéma, on peut conclure que ce remède était devenu nécessaire" [se o livro recebeu seu antídoto no cinema, pode-se concluir que este remédio tinha se tornado necessário] (EPSTEIN, 1947: 23). Qual seria, entretanto, esse remédio que parece complementar o que faltava à literatura?

\section{A catarse demoníaca}

A pista que Epstein oferece recai no poder do cinema de, imitando a psicanálise, ajudar a despistar e vencer determinado recalque individual ou coletivo. $\mathrm{O}$ antídoto pode ser entendido, de fato, pela sua ação catártica, sedativa e terapêutica no que concerne ao descontentamento e a agitação popular. Esta "hygiène mentale" (EPSTEIN, 1947: 27), função pública e imprescindível ao equilíbrio psíquico, é o que o autor considerava, na primeira metade do século XX, um dos bens do cinema. E também uma válvula de escape que, no contexto atual, parece estar imbuída de ainda maior coerência.

\footnotetext{
${ }^{2}$ Apesar de ser reconhecido por seus estudos teóricos, Jean Epstein é mais lembrado pela sua contribuição cinematográfica, pela qual é tido como um precursor de inúmeros movimentos e linguagens. O uso da câmera lenta, os ensaios de variação e de velocidade e a exploração da "quarta dimensão" são algumas dessas contribuições (DUBOIS, 2004: 208). É de Epstein os filmes "Cœur Fidèle" (1923), "La Chute de la Maison Usher" (1928) e "Finis Terrae" (1929), entre outros.

${ }^{3}$ Epstein designa de cinema "a caligrafia na qual a imagem é um signo complexo e preciso" (KLINE, 2010: 9).
} 
Afinal, com o rápido declínio da poesia e da literatura em geral, o cinema puxou para si não apenas aquele público que sublimava suas aspirações a partir das palavras de outrem, mas aquela parcela muito mais abrangente da sociedade que o texto é incapaz de abraçar, como os semi-analfabetos e os analfabetos. A importância do cinema, pois, recai não somente no seu inegável valor artístico, mas também na sua capacidade de evitar a concretização de atitudes que, se efetivadas na sociedade, conduziriam a desordens e à destruição da harmonia da vida pública.

É por essa responsabilidade de larga-escala, assegura Epstein por meio de uma sociologia do cinema ${ }^{4}$, que os filmes de gangsters são mais úteis e "dangereusement prodigues" [perigosamente pródigos] (EPSTEIN, 1947: 74) que os bem-pensantes, desprovidos que são de valor poético e pouco capazes de ação moral. Dessa maneira, quando a sociedade impõe a sublimação de costumes individuais em função das necessidades da comunidade, o homem tem outra forma (além da do sonho) de satisfazer suas tendências reprimidas.

Pois o cinema, assim como o sonho, isola o que Epstein apelida de "detalhes representativos", desenvolvendo tempos próprios e descrevendo de forma apropriada a vida mental profunda ${ }^{5}$. Mais importante ainda, tanto a imagem onírica quanto a cinematográfica são representações simbólicas de idealização sentimental e, uma vez que assim o é, nada é logicamente ou racionalmente impossível. Os espectadores, com isso, recebem a chance de trilhar caminhos revolucionários e, assim, satisfazer sem danos concretos "les ferments démoniaques d'agitation" [os fermentos demoníacos de agitação] (EPSTEIN, 1947: 29).

\section{A multiplicidade do ser}

É com esse e outros sentidos que o autor declara que o cinema ocasiona o redescobrimento de si próprio, revelando aspectos que não figuram no espelho e na fotografia. No cinegrama, o "eu” é uma variável complexa e relativa, além de simultaneamente desigual em si mesma (o teórico declara polimórfica) e dissoluta

\footnotetext{
${ }^{4} \mathrm{O}$ termo indica "a análise da relação entre os temas das obras e a sociedade na qual elas foram produzidas e recebidas", bem como um "estudo das representações fílmicas porquanto elas se desenrolam em um certo âmbito social” (AUMONT e MARIE, 2003: 274).

${ }^{5}$ Essa tese foi retomada na década de 1970 por Jean-Louis Baudry e Christian Metz, críticos que defendem a existência de um caráter visual comum entre o cinema e o devaneio. Isso seria possível devido à grande liberdade de manobra e também à ausência de imagens atadas por vínculos temporais, espaciais ou lógicos, fatores que traduzem o "sonho acordado" - i.e., a vida psíquica diurna (AUMONT e MARIE, 2003: 277).
} 
(amorfa). Logo, não é possível falar em individualidade na tela, uma vez que a aparência desta é, em essência, um jogo móvel de infinitos aspectos transitórios.

Para sustentar o argumento de que o excesso de possibilidades do ser dispersa a probabilidade de realização, Epstein liga o não auto-reconhecimento de um ator ou figurante (que nega ser aquela figura que vê na tela) com os fundamentos do princípio de Pauli e das desiguldades de Heisenberg. A associação é brilhante e extrapola os limites do cinema; para o autor, o homem é o resultado de um cálculo "dont la netteté et la constance spécifiques sont imaginaires et couvrent une large zone d'innombrables réalisations approximatives possibles" [do qual a nitidez e a constância específica são imaginárias e cobrem uma ampla zona de inumeráveis realizações aproximáveis possíveis] (EPSTEIN, 1947: 66).

Seria, talvez, o caso do "Ninguém" (que é alguém) tratado por Homero, Shakespeare e Lewis Carroll, mas com uma força que supera a linguagem, uma vez que é solidificada pela imagem cinematográfica. Toda dificuldade que o cinema encontra para tratar de ideias racionais é portanto balanceada - e às vezes até ultrapassada - pela facilidade com que traduz a poesia das imagens, aquela da metafísica do sentimento e do instinto (EPSTEIN, 1947: 12).

\section{0 prospecto não-uingado}

Influenciado pelos cineastas Fernand Léger e Abel Gance, Epstein se associou ao movimento impressionista francês e desenvolveu, também no plano teórico do qual Le cinéma du diable é exemplo, a ideia de que o cinema atinge seu melhor desempenho quando emprega o organismo do sonho como forma primordial de pensamento. Ele acreditava que se os filmes "imitassem" a expressão sutil e potente dos sonhos, haveria algo como uma reforma fundamental da inteligência (EPSTEIN, 1947: 28) capaz de se aproximar significativamente à realidade subjetiva/verdadeira da existência.

Meio século mais tarde, o mercado de filmes está recheado de intenções de trabalhar o espaço-tempo a partir da expressão onírica. A efeito de exemplo, pode-se citar títulos como "Science of Sleep" (2006, Michel Gondry), "Waking Life" (2001, Richard Linklater), “Abre los ojos” (1997, Alejandro Amenábar) e, de maneira geral, os longasmetragens de David Lynch. Contudo, a popularidade crescente do cinema não provocou, 
com raras exceções ${ }^{6}$, a subsequente originalidade de tema e de tratamento idealizadas por Epstein. Talvez o sonhado potencial de levar à eficácia "quasi magique" (EPSTEIN, 1947: 28) da representação transcartesiana estivesse mais próximo do cinema experimental francês, iniciado nos anos $1920^{7}$, do que dos nossos cineastas contemporâneos.

\section{Referências Bibliográficas}

\section{Em livros}

AUMONT, Jacques e MARIE, Michel. Dicionário Teórico e Crítico de Cinema. Campinas: Papirus, 2003.

BEAVER, Frank. Dictionary of Film Terms. New York: Peter Lang Publishing, 2007.

KLINE, Thomas Jefferson. Unraveling French Cinema. Chichester: Wiley-Blackwell, 2010.

DUBOIS, Philippe. Cinema, Vídeo, Godard. São Paulo: Cosac \& Naify, 2004.

XAVIER, Ismail. [org.] A Experiência do Cinema. São Paulo: Graal, 1983.

\section{Em revistas}

CORTADE, Louis e LAPIDUS, Roxanne. Le Cinéma du Diable (artigo). Substance (revista científica), vol. 34, número 3, 2005, pp.3-16.

\section{Em site}

EPSTEIN, Jean. Le Cinéma $d u$ Diable. Paris: Jacques Melot, 1947. In: http://classiques.uqac.ca/classiques/. Acesso em 03/04/2011.

\footnotetext{
${ }^{6}$ Críticos tendem a encarar os filmes "Slaughterhouse Five" (1972, George Roy Hill), "My Own Private Idaho" (1991, Gus Van Sant) e "Three Women" (1977, Robert Altman) como longas-metragens que operam de maneira onírica, seja pela falta de continuidade, seja pela maneira ilógica e não-sincronizada pela qual as imagens aparecem e escapam da tela (BEAVER, 2007: 82).

${ }^{7} \mathrm{O}$ movimento francês avant-garde foi uma reação contra o "cinema narrativo", tendo se desenvolvido por meio de experimentos abstratos, expressionistas e surrealistas. Devido aos seus truques de câmera, foi também cunhado de "cinema puro" (BEAVER, 2007: 90).
} 